\title{
A 3D BASED APPROACH TO THE ARCHITECTURAL STUDY OF THE ROMAN BATH AT THE SANCTUARY OF APOLLO HYLATES (KOURION, CYPRUS).
}

\author{
M. Faka a*, S. Christodoulou b, D. Abate a, C. Ioannou a, S. Hermon a \\ a Science and Technology in Archaeology Research Center, The Cyprus Institute, Nicosia \\ (m.faka, d.abate, c.ioannou s.hermon)@ cyi.ac.cy \\ b Archaeological Research Unit, University of Cyprus \\ christodoulou.paraskevi@ucy.ac.cy
}

\section{Commission II}

KEY WORDS: Image based technique, Range based technique, Virtual reconstruction, Roman baths, Cyprus

\begin{abstract}
:
Roman baths represented a popular social practice of everyday life, cited in numerous literary sources and testified by ample archaeological remains all over the Roman Empire. Although regional studies have contributed extensively to our knowledge about how baths functioned and what was their social role in various regions of the Mediterranean, their study in Cyprus is yet to be developed. Moreover, despite the increasing availability of devices and techniques for 3D documentation, various characteristics, especially in relation to the heating and water supply system of the baths, were omitted and were not properly and accurately documented. The pilot case study outlined in this paper presents the 3D documentation of the Roman bath, excavated in the 1950s, within the area of the Sanctuary of Apollo Hylates at Kourion (Limassol district). The creation of an accurate 3D model of the documented area through image and range based techniques combined with topographic data, allows the detailed analysis of architectural elements and their decorative features. At the same time, it enables accurate measurements of the site, which are used as input for the archaeological interpretation and virtual reconstruction of the original shape of the bath. In addition, this project aims to answer a number of archaeological research questions related to Roman baths such as their architectural features, function mode, and technological elements related to heating techniques.
\end{abstract}

\section{INTRODUCTION}

The paper describes the procedure followed for the 3D documentation of the Roman bath at the Sanctuary of Apollo Hylates. Prior to the research described below, which originates from the $\mathrm{PhD}$ dissertation of one of this paper's authors focusing on the architectural and technological elements of the bathbuildings, only a single traditional printed 2D plan of the archaeological site (Figure 1) was available bearing intrinsic scale factor errors due to the original survey technique applied (Scranton, 1967). Hence, the need for a complete geometrical documentation of the bath structure became essential for a comprehensive study of its architecture and function.

\subsection{Aims of the Project}

Considering the growing interest in the technological and sociocultural study of the thermal baths, a multi-disciplinary research approach was designed, in order to:

- Create an accurate 3D modelling pipeline for the documentation of bath structures through image and range based techniques combined with topographic survey, which allows detailed analysis of the architectural elements and decorative features, considering their morphology, structural elements and water supply systems. Moreover, the obtained 3D model enables precise measurements of the site, to be used as input for the archaeological interpretation and virtual reconstruction of the original shape of the bath, a task otherwise impossible to complete if relying only on the previously available printed material.

- Answer a number of archaeological research questions related to Roman baths, such as functional and technological elements associated with the heating system. Through a critical analysis, the basis for further discussion will be established as well as comparison with other baths on the island with similar characteristics.

The aforementioned outcomes are used for the following tasks:

- Reconstruct the original shape of the structure through computer graphic techniques, and virtually simulate the environment and function of the bath, based on the archaeological remains.

- Promote the cultural heritage of Cyprus and archaeological value of baths to the wider public (pupils, students, tourists), archaeologists and academics, and disseminating, according to the EU Open Access (OA) guidelines, 3D high resolution models via web.

* Corresponding author 


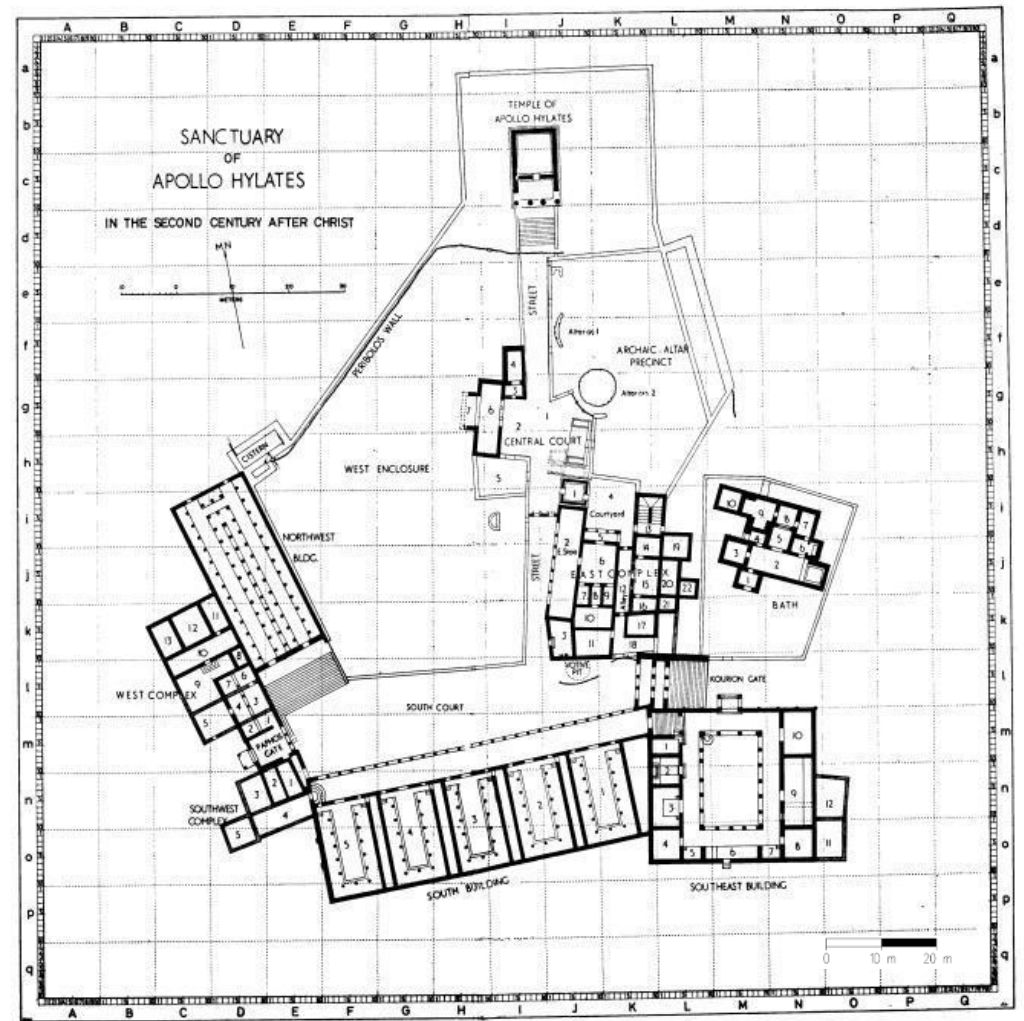

Figure 1. Plan of archaeological area of the Sanctuary of Apollo Hylates, Kourion (Scranton 1967, plan 1).

\subsection{Related Works}

The documentation of heritage assets has seen in the last decades an important growth in terms of technology-ready availability and common recording oriented efforts. The two main areas in which these activities can be mainly divided are represented by reality based modelling and non-reality based modelling approaches.

Reality based reconstructions imply the presence of physical remains which are usually digitised by means of active and passive sensors. The Forum of Pompeii (Guidi et al., 2009) has been recorded exploiting a multi-resolution approach. (Remondino et al., 2009) experimented a reality-based, multiresolution and multi-source documentation, and a digital reconstruction of a part of the ancient Maya kingdom of Copán, Honduras, providing digital 3D models for research and public education purposes.

Furthermore, non-reality based reconstructions are realised using traditional computer graphics techniques coupled with philological studies, ancient sources as well as automatic procedural modelling methodologies. (Fischer, 2011) proposed an immersive and virtual environment of the historical site of Williamsburg (USA). The project re-created the cityscape of the colony before the American Revolution. The reconstruction started with the review of the existing evidence and the examination of the prevailing suppositions. Finally, a full model of the city was realised using a computer-aided drafting software. Rome Reborn Project is a virtual reconstruction of the entire city of ancient Rome at the height of its urban development in AD 320 (Dylla et al., 2009). The version 2.0 has been realised using a procedural modelling approach. The city Plastico, located in the Museum of Roman Civilisation in Rome, was previously 3D scanned (Guidi et al., 2005) and its digital version was used as base for the positioning of each building.
Focusing more on the details of reconstructing bath structures in archaeological context, different initiatives had been performed. The majority of these studies is based on the digitisation of archaeological remains, which served as footprints for the reconstruction of the lost structures. (Vico and Vassallo, 2010), exploiting computer graphic techniques, analysed and computed structural calculations in relation to the stability of the vaults of the baths found in the Villa of Livia in Rome. (Blanco and Pucci, 2012) documented and studied the boiler room in the Small Baths of the Hadrian's Villa in Tivoli, allowing for the first time the analysis of the baths' heating system. A digital reconstruction of the Roman baths of Caracalla was proposed by (Oetelaar, 2013), focusing on the digital process undertaken to obtain the geometry of a room for the purposes of thermal analysis. At the same time, the 3D model allows experiencing the atmosphere of the site and illustrates the huge surrounding structures.

The balneum of a Roman villa in Slovenia (Lavrič, 2015) was digitally reconstructed using traditional survey techniques, such as Total Station and GPS coupled with CAD software. This study allowed to perform a detailed architectural and stylistic study of a rare structure in the region landscape through the anastylosis process of the preserved remains. In (Rubinich, 2011) a multilevel study, comprising a topographic survey, GIS analysis and 3D reconstruction, is illustrated for the Great Baths of Aquileia (Italy). The results of the virtual reconstructions aim to valorise the site for didactic purposes.

In (Capozzi et al., 2016) a non-reality based approach is proposed for the valorisation of the thermal complex of the Archaeological Park of Baiae. A philological procedure has been followed in relation to the study of the ruins, the landscape and the knowledge of the ruin's own spatial elements. (Porcelli et al., 2013) analysed the process of reconstructing the Roman Baths of Edeta, Llíria (Spain) through 3D scanning technology and 3D virtual 
reconstruction. This approach has been used both for further scientific analysis and for public disclosure of the archaeological complex.

The Acquae Patavinae Project (Ferdani et al., 2014) aims to improve the knowledge of the thermal landscape in the area surrounding the city of Padova (Italy) through 3D online web technologies.

\section{DESCRIPTION OF THE SITE}

\subsection{Roman Baths in Cyprus}

Archaeological excavations to date uncovered the remains (or associated material) of a total of 25 bath buildings in Cyprus, both public and private (Christodoulou, 2014). These are distributed along the coastline of the island. Only two baths are hitherto known to be located in the hinterland, in the mountainous area of Troodos. Out of them three are dated to the Hellenistic period, eighteen to the Roman and four to the Byzantine times. Their dating is usually based on the study of archaeological data, mainly pottery and epigraphic evidence, rather than on a thorough analysis of their architecture, masonry type and heating techniques. Epigraphic evidence, although scanty, sometimes provides information on the construction, restoration and embellishment of baths or other associated constructions, such as aqueducts, gymnasia etc. Of the bath-buildings attested epigraphically, only three can be associated with certainty with actual archaeological remains: amongst them the baths at the Sanctuary of Apollo Hylates at Kourion (McFadden, 1950).

From the evidence attested so far, Cypriot baths consist of a row, or angular, arrangement of three rectangular rooms, usually the heated rooms, with adjoining ones that could facilitate extra amenities offered in the baths. The bathing route of the baths is mainly retrograde; in other words, the bather progressed forward through a succession of rooms and then retraced his/her steps to the starting point. By contrast, in the case of "imperial-type" baths, the bather progressed through a sequence of rooms, which led him/her back to the starting point without necessarily having to retrace his/her steps. Almost all the baths uncovered in Cyprus are of a rather small size, covering on average an area of 150-300 square meters. Only two bath complexes are distinguished by their larger scale, covering an area of approximately 3,500 square metres, and could be compared with the large imperial thermae at the large centres of the Empire.

It is difficult to determine with confidence the private or public character of the majority of these baths, and further research is needed towards this end. Amongst the identifiable public baths, at least three are found in the vicinity of cult places. The baths at the Sanctuary of Apollo Hylates at Kourion, located just east of the temple, were probably used by pilgrims.

Among the three known heating techniques employed in Roman baths, only two are recorded on the island. The most commonly used technique in the Roman Empire, that employing tegulae mammatae, is not hitherto attested in Cyprus. The tubulus, (a certain type of specially cut flues set within the thickness of the wall) is an equally well known heating technique that is attested only in two Cypriot baths. Finally, the terracotta spacer technique, employing plugs or pins, is also known in three baths, and amongst them the baths at the Sanctuary of Apollo Hylates.

\subsection{The Roman Bath at the Sanctuary of Apollo Hylates (Kourion, Cyprus)}

Five baths were uncovered in the archaeological area of Kourion, testifying the importance of baths during Roman times. In the eastern area of the Sanctuary of Apollo Hylates, a public bathing establishment was found during the 1950s excavations (McFadden, 1950; Scranton, 1967; Buitron, and Soren, 1982). It is dated by an inscription to 101/2 AD (Mitford, 1971, McFadden, 1950). The baths were entered from the south through a vestibule and a long hall. The rooms adjoining the long hall to the west and to the north served as apodyteria (changing room), while the room in between was probably a service room (McFadden, 1950). Plunge pools paved with mosaics, used for cold baths, were found at the east end of the long hall (an outer frigidarium), and almost certainly an inner frigidarium. Bathers could then proceed successively to warmer rooms, from the tepidarium (medium room) and sudatorium (sweat room) to the caldarium (hot room) which immediately adjoined the furnace to the west end. Two recesses on the south and west walls of the caldarium were evidently used as alvei (hot pools for individual use). In this way the bathers followed a gentle transition to the outdoor atmosphere by returning in gradual stages the way they had come in.

The heat was transmitted from the hypocaust (underfloor heated area), with the suspensurae (raised floor) made of square pilae, to the caldarium and sudatorium, where most of the heat was required, and the northern part of the tepidarium, and by hollow panelling in the walls and the application of a system of terracotta spacers. A few examples of rectangular terracotta plugs, described by (Scranton, 1967) as "hollow-wall peg tiles", were found (Figure 2). They consisted of a rectangular block of terracotta of a rather coarse fabric (about $26 \mathrm{~cm}$ long, $8 \mathrm{~cm}$ wide and $55 \mathrm{~cm}$ high). These pegs were built into the wall and their projecting part, some $16-18 \mathrm{~cm}$ long, had two grooves. The terracotta tiles that lined the walls slotted into one, while the terracotta tiles that formed the outer surface of the wall slotted into the other (Christodoulou, 2014). The gap in between, about $10 \mathrm{~cm}$ long, served as a passage for the hot air. The holes, into which the pegs fitted, are visible on the face of the wall of the caldarium and the sudatorium. As indicated by the evidence, the pegs were distant by about $50 \mathrm{~cm}$ from each other (Scranton, 1967). A coat of mortar was smeared over the outer face of the wall, which was then covered by thin marble slabs, held in place by bronze clamps, which masked the end-face of the pegs.

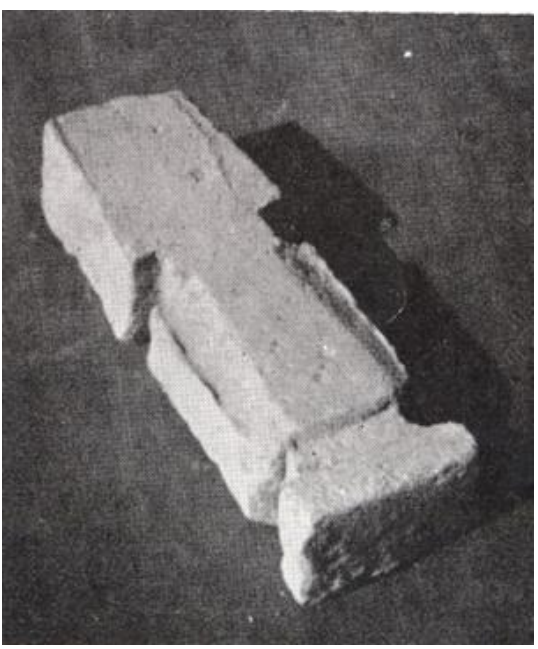

Figure 2. "Hollow-wall peg tile" from the baths of the Sanctuary of Apollo Hylates (Scranton 1967, fig. 60c). 


\section{METHODOLOGY}

\subsection{Data Capture and Post Processing}

During May 2014, a fieldwork campaign was carried out at the archaeological site of Apollon Hylates and particular in the area of the Baths. Image and range based modelling techniques were applied for the digitisation of the site, combined with topographic measurements.

\subsection{Range Based Techniques and Digital Imagery}

A phase shift laser scanner, with a certified accuracy of $3 \mathrm{~mm}$ at $3 \mathrm{~m}$, was used for the creation of a high resolution 3D point cloud of the archaeological structures describing all the morphological features and architectural details. In order to avoid any shade, and due to the complexity of the bath remains, the scanner was placed in 42 positions, either on the ground or over the tripod, yielding an average distance scanner-object of $5 \mathrm{~m}$.

The X-Y resolution for each point cloud was calculated in 3.6 $\mathrm{mm}$, equivalent to 25 line per degree (LPD). However, the resolution can be considered higher due to the overlapping of the different point clouds and the redundancy of the 3D data. The final model consisted of $\sim 760$ million points, with an average point count of 18 million per scan (Table 1).

\begin{tabular}{|c|c|c|c|}
\hline $\begin{array}{c}\text { Scan } \\
\text { Station }\end{array}$ & $\begin{array}{c}\text { Distance } \\
\text { scanner-object }\end{array}$ & $\begin{array}{c}\text { Average } \\
\text { resolution per } \\
\text { scan }\end{array}$ & $\begin{array}{c}\text { Final point } \\
\text { cloud }\end{array}$ \\
\hline 42 & $5 \mathrm{~m}$ & $3.6 \mathrm{~mm}$ & 760 mil points \\
\hline
\end{tabular}

Table 1. Range based technique details

Following the next stage of the post processing, a common pipeline for TLS data was applied (Mills, 2011; Grussenmeyer, 2016). A final merged point cloud with an average spacing among points of $1 \mathrm{~cm}$ was obtained after decimation (Figure 3 ). This resolution has been considered sufficient for the specific purposes of this study. The point cloud was then converted in a watertight mesh model applying a dedicated surface reconstruction algorithm (Bolitho et al., 2009).

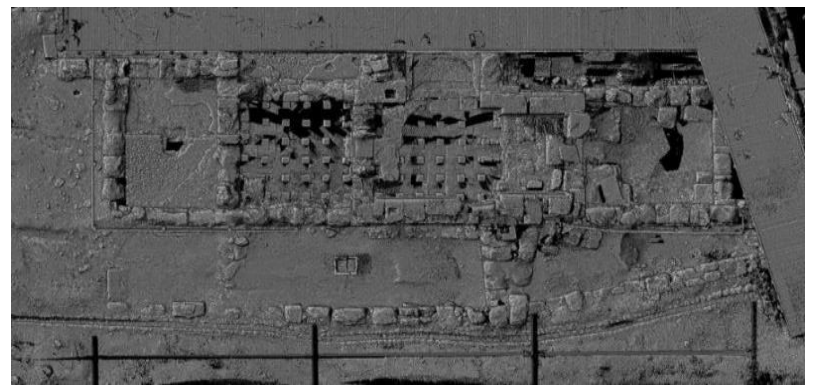

Figure 3. Top view of the 3D Model of the Roman baths area, range based reconstruction.

Aiming at creating a high resolution orthophotos and applying RGB values to the reality based bath 3D model, an image based survey have been realised (Stylianidis, 2016). For this purpose, a Canon EOS 600D, 18 - megapixel sensor device, equipped with

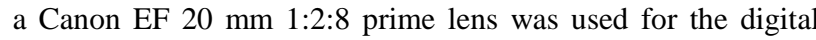
images acquisition (Table 2). The expected ground sample distance (GSD), calculated in accordance with the planned camera network, was $0.95 \mathrm{~mm}$. 740 images were taken depicting part of the monument and in specific, more detailed documentation of the hot room (caldarium) and the sweat room (sudatorium). The image dataset has been processed in Agisoft Photoscan until an RGB scaled high resolution 3D model has been created (Figure 4).

\begin{tabular}{|c|c|c|c|}
\hline $\begin{array}{c}\text { Taken } \\
\text { images }\end{array}$ & $\begin{array}{c}\text { Distance camera- } \\
\text { object }\end{array}$ & GSD & $\begin{array}{c}\text { Dense point } \\
\text { cloud }\end{array}$ \\
\hline 740 & $3 \mathrm{~m}$ & $0.95 \mathrm{~mm}$ & 49 mil point \\
\hline
\end{tabular}

Table 2. Image based technique details

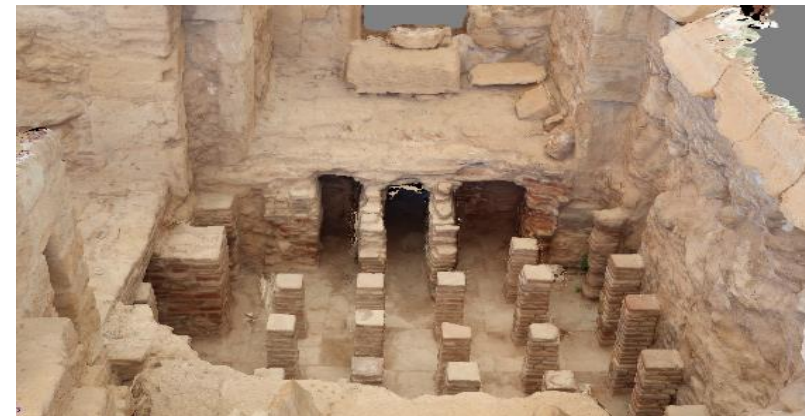

Figure 4. 3D Model of the hypocaust area, image based reconstruction

Digital high resolution orthophotos have been created with a pixel size dimension of $1 \mathrm{~mm}$ (Figure 5). These orthophotos have been then imported in a CAD environment to manually produce traditional and updated CAD drawings (plans and sections).

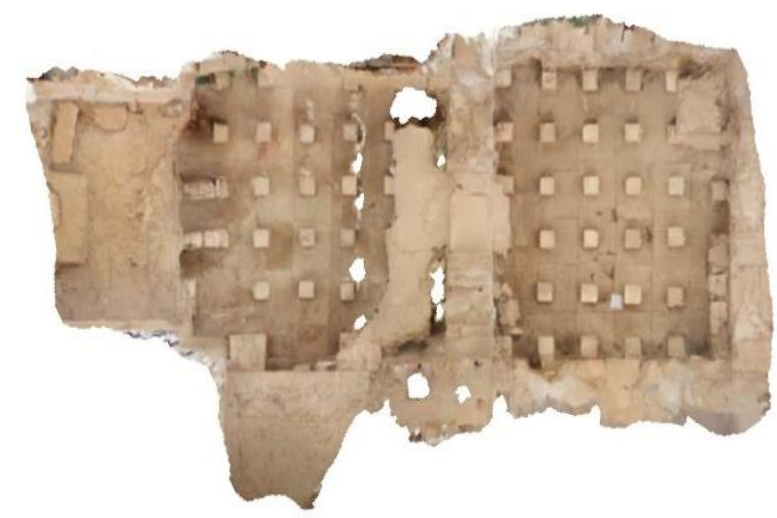

Figure 5. Orthophoto of the caldarium (on the left) and of the sudatorium (on the right).

To improve the accuracy of the digitisation process and integrate the different dataset in a common reference system, a topographical network was established by means of Total Station and GPS (Figure 6). The network allowed the acquisition of the necessary measurements of the ground control points (GCP) previously placed on site in all directions. The measurements of the network resulted to an adjustment accuracy of less than $15 \mathrm{~mm}$. The 3D model was eventually geo-referenced in absolute coordinates within the Cyprus Geodetic Reference System (LTM CGRS93).

The obtained reality based textured bath mesh model was finally used as footprint for the virtual reconstruction by means of computer graphic techniques. 


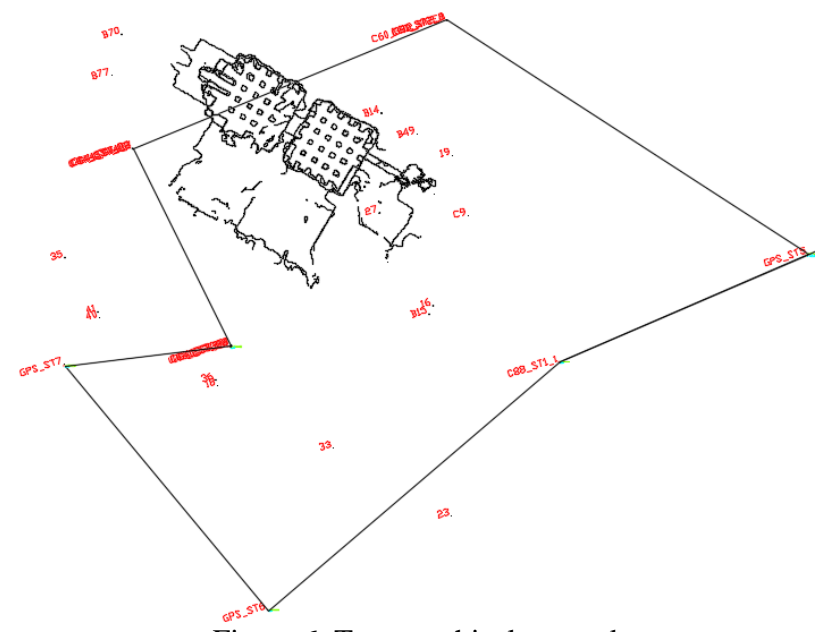

Figure 6. Topographical network

\subsection{Virtual Reconstruction of the Roman Baths}

The virtual reconstruction was made according to the 4.6 article of the London Charter for the computer-based visualisation of Cultural Heritage, which states that the "Documentation of the evaluative, analytical, deductive, interpretative and creative decisions made in the course of computer-based visualisation should be disseminated in such a way that the relationship between research sources, implicit knowledge, explicit reasoning, and visualisation based outcomes can be understood (Denard, 2009; Nicolucci and Hermon, 2010).

The digital reconstruction of the baths has been created using the Autodesk 3D Studio Max software and rendered with Mental Ray. The initial input has been represented by the aforementioned reality based model, which served as canvas for the elevation and extrusion of the missing parts and elements within a structural bottom-up approach.

The study of the architectural and technological features of the baths is probably the most crucial components of the proposed approach. This is essentially an interdisciplinary project that combines traditional methods of archaeological investigation with methods currently developed in the field of digital humanities, for a more complete and detailed assessment of the bath-buildings. The 3D scanning procedure, along with the archaeological remains, associated archaeological finds and published material from the 1950s excavations (McFadden 1950; Scranton 1967) provided enough ground to set up a 3D reconstruction. The latter was also based on the broader research conducted on architecture of Roman baths uncovered in Cyprus, although most of them are of different size, and in poor state of preservation.

The virtual scenario of how the baths used to be starts with the wall extrusion from the remaining buildings footprints, which are undoubtedly correct (Figure 7). At the same time, part of the floor layers and most of the hypocaust system survives in situ, so it could be reconstructed with great certainty (Figure 8). Striking is the fact that this small bath follows almost all recommendations by Vitruvius $(\mathrm{V}, 10)$ regarding the construction and heating techniques that should be applied for the maximum exploitation of the heat.

One of the most puzzling issues is definitely the exact height of the structure as well as the roofing. Since other classic architectural proportions recommended by Vitruvius are followed, we would assume, with great caution, that a proportion 1:3 would be applied here as well. We would assume that a barrel vault would cover the heated rooms, based also on the uncovered voussoirs during the 1950 excavations. According to the excavators, the diameter of the vault would be around $2,15 \mathrm{~m}$ (Scranton, 1967). Based on the evidence of the remaining

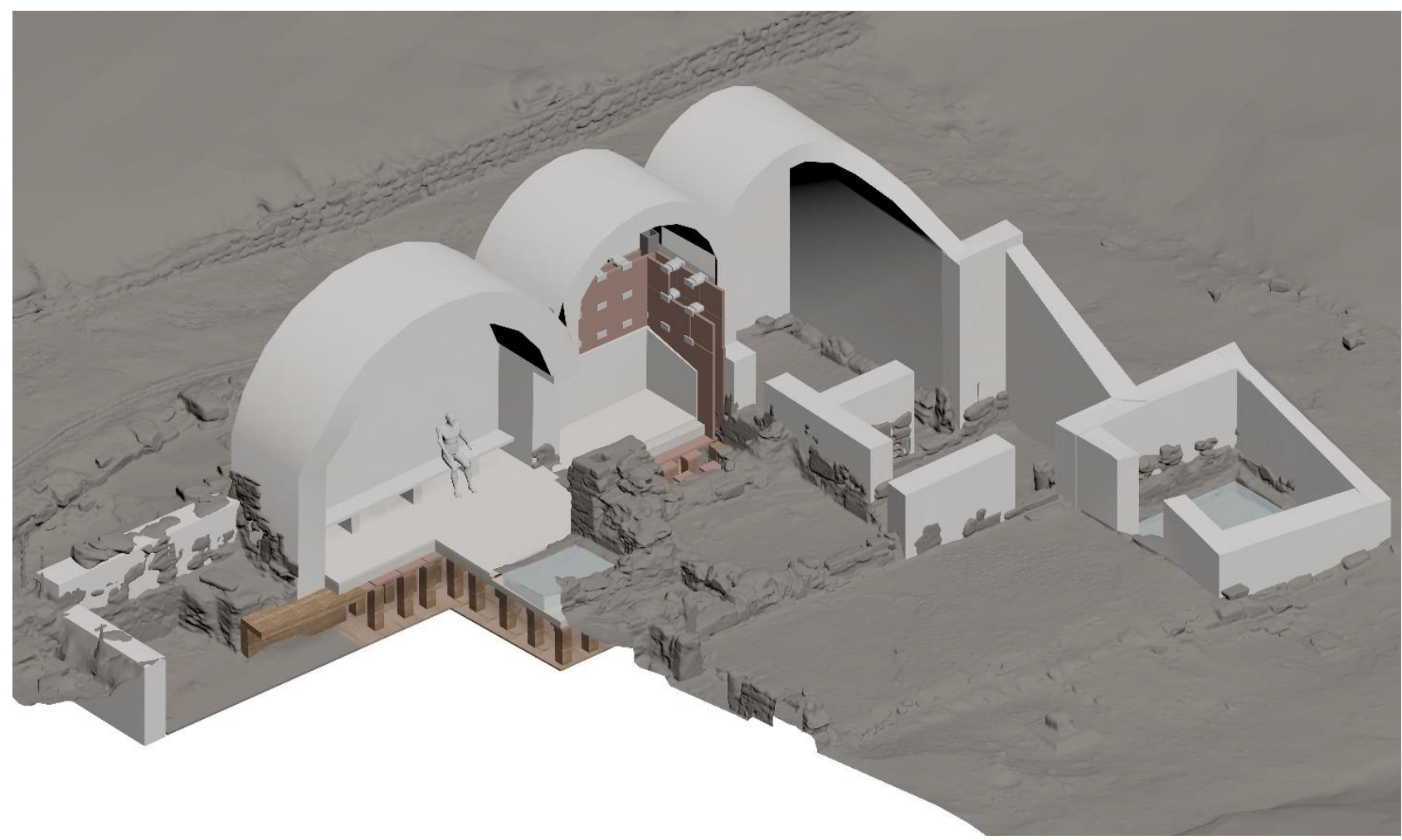

Figure 7. Virtual reconstruction of the bath, Axonometric view 
terracotta pins attached to the wall, the restored walls reach the height of approximately 4.5 meters. In general, efforts have been made to analyse and recreate the different building modules of the bath. Each module is represented with a different colour and there is no use of realistic texturing, in order to illustrate and differentiate the existing part of the site with the digital reconstructed part. Furthermore, due to the lack of information about the materials in various parts that were originally used, as well as later interventions, the team avoided to mimic elements, materials that may have not been applied to this site.

\section{NEW PERSPECTIVES AND ASSESSMENTS}

As it has been already mentioned in the introduction, bath studies in Cyprus did not receive any attention before. Various elements and characteristics from the building themselves, such as the function of the heating system and the water supply, were hence not properly and accurately documented and studied. Amongst the numerous archaeological remains of baths excavated in Cyprus, the baths at the Sanctuary of Apollo Hylates were chosen for this first attempt of $3 \mathrm{D}$ documentation and reconstruction. Based on four mainly criteria: the good preservation state of the structure; its accessibility and feasibility for documentation due to its relevant small size; the abundant archaeological evidence and published information (and unpublished material) in relation to the heating techniques of the bath.

The analysis of the digital data allowed the identification of various structural features of the building otherwise not visible, either because they were not accessible or hidden. In specific, owing to the application of various shading algorithms it was possible to spot a series of holes used for the application of terracotta spacer pin (Figure 9). This major discovery, along with the uncovering of a few terracotta spacer plugs, supports the theory that the baths were employed with the terracotta spacerpin heating technique.

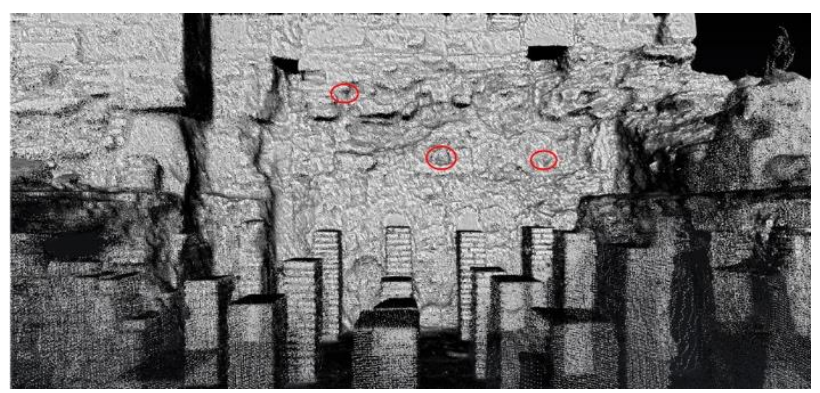

Figure 9 . Radiance scaling visualization of the 3D point cloud. Identified hole features (intended to hold in place the spacer plugs)

Moreover, thanks to the bath 3D model, an accurate assessment of the volume of the underfloor environments (caldarium and sudatorium, $9.2 \mathrm{~m} 3$ each) and of the furnace (praefurnium) have been computed. This analysis will allow to understand the amount of steam, and hence water and fire, produced to warm up the main room, as well as the amount of natural supplies needed to power the entire structure.

\section{CONCLUSIONS AND FUTURE WORK}

The documentation of the baths of Apollo Hylates represents a pilot case study for the documentation and digitization of the remaining four baths of the archaeological site of Kourion. Such an approach will allow an inter-site comparison for the identification of architectural, technological and stylistic similarities or differences (dating to various chronological periods, of different size, function mode, heating techniques).

Future efforts will focus both on fluid-dynamic studies of the baths as well as on dissemination activities which are intended to address the public and the scientific community.

Currently the analysis and interpretation of the archaeological remains, even though they have highlighted some technological aspects, still they do not allow reaching exhaustive conclusions on how fluid-dynamic operated through the entire bath heating system. The contribution of Computational Fluid Dynamic

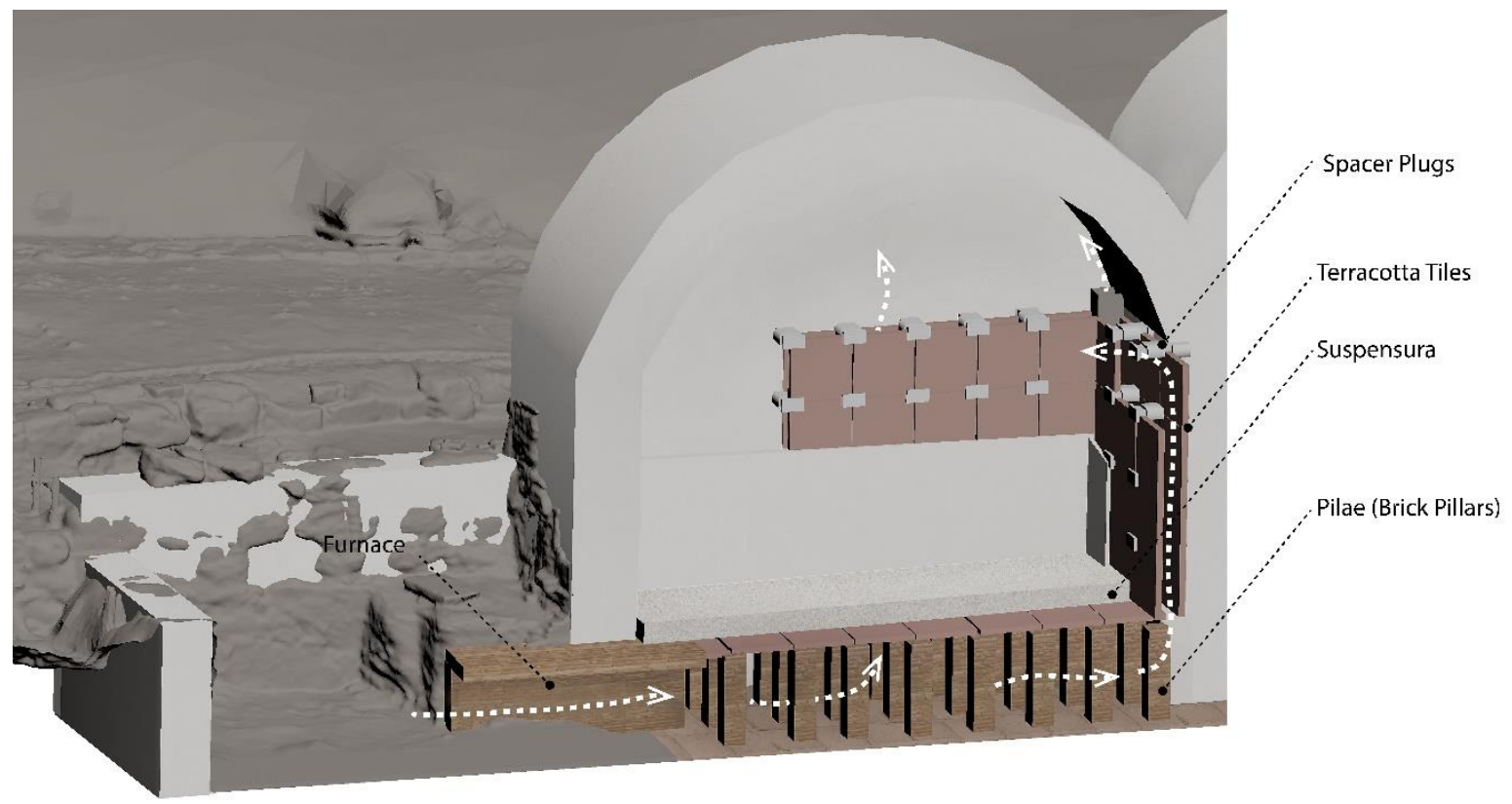

Figure 8. Virtual reconstruction of the bath, section of the praefurnium and caldarium 
(CFD) coupled with advanced simulation will allow to process complex models and systems and increase the knowledge on this complex environment.

Through a dissemination strategy, interactive 3D models, metadata and archaeological information will be circulated accordingly, depending on the different group of users. A scientific oriented 3D model incorporating the relevant archaeological terminology for the baths, could be a powerful tool for archaeologists and academics. On the other hand, a descriptive 3D model could be used for the promotion of the cultural heritage of Cyprus and archaeological value of baths.

\section{ACKNOWLEDGEMENTS}

The authors wish to acknowledge the Director of the Department of Antiquities of Cyprus for granting kind permission for the work undertaken at the archaeological site of Kourion. Also, our former colleague Giancarlo Iannone for his crucial involvement and assistance at the beginning of the project.

\section{REFERENCES}

Blanco, A., Pucci, M., 2012. The boiler room of the Small Baths in Hadrian's villa. Excavation, analysis, preservation. Proc. 17th International Conference on Cultural Heritage and New Technologies Vienna, Austria.

Bolitho, M., Kazhdan, M., Burns, R. and Hoppe, H., 2009. Parallel poisson surface reconstruction. Advances in Visual Computing, pp.678-689.

Buitron D., Soren D., 1982. Sanctuary of Apollo Hylates. In H.W. Swiny, An Archaeological Guide to the ancient Kourion area and the Akrotiri Peninsula, Nicosia, 1982, pp. 58-66.

Capozzi, R., Picone, A., Visconti, F., 2016. Archaeology, Architecture and City. The enhancement project of the archaeological Park of the baths of Baiae. International Journal of Architectural Research, Vol. 10, March 2016, pp.113-130.

Christodoulou, S., 2014. Hellenistic and Roman Baths in Cyprus, University of Cyprus (unpublished PhD thesis), Nicosia.

Denard, H., 2009. King's College London, 7 February 2009 (http://www.londoncharter.org/fileadmin/templates/main/docs/l ondon_charter_2_1_en.pdf) last access 29.05.2017

Dylla, K., Frischer, B., Mueller, P., Ulmer, A., Haegler S., 2009. Rome Reborn 2.0: A Case Study of Virtual City Reconstruction Using Procedural Modelling Techniques. CAA 2009. Making History Interactive. 37th Proceedings of the CAA Conference March 22-26, 2009, Williamsburg, Virginia (Archaeopress: Oxford, 2010), pp. 62-66.

Ferdani D., Fanini B., Baldassari G. L., Cerato I., Pescarin S., 2014. Handling Transparency in 3D Reconstructed Online Environments: Aquae Patavinae VR Case Study. Proc. 40th Annual Conference of Computer Applications and Quantitative Methods in Archaeology (CAA), pp. 165-173.

Fischer, Lisa E., 2011: Visualizing Williamsburg: Modelling an Early American City in 2D and 3D. Proc. VAST 2011 Short and Project Paper Proceedings. 12th International Symposium on
Virtual Reality, Archaeology, and Cultural Heritage, 18th-21st October 2011, Prato, Italy.

Guidi, G., Micoli, L., Russo, M., Frischer, B., De Simone, M., Spinetti, A., Carosso, L., 2005. 3D digitization of a large model of imperial Rome. In: International Conference on 3-D Digital Imaging and Modelling, pp. 565-572.

Grussenmeyer, P., Landes, T., Doneus, M., Lerma, J.-L. (2016). Basics of Range-Based Modelling Techniques in Cultural Heritage (Chapter pp. 305-368). In: 3D Recording, Documentation and Management of Cultural Heritage.

Guidi, G., Remondino, F., Russo, M., Menna, F., Rizzi, A., Ercoli, S., 2009: A Multi-resolution methodology for the 3D modeling of large and complex archaeological areas. International Journal of Architectural Computing, Vol. 7(1), pp. 39-55.

Lavrič, M., 2015. 3D Reconstruction of a Balneum in a Roman Villa Rustica, Mošnje, Slovenia. Proc. 2nd International Congress on Digital Heritage 2015, Vol 2, Digital Heritage Projects And Applications.

McFadden, G.H., 1950. Kourion, the Apollo Baths. University Museum Bulletin14, pp.14-25.

Mills, J., 2011. 3D Laser Scanning for Heritage (second edition) Advice and guidance to users on laser scanning in archaeology and architecture.

Mitford, T.B., 1971. The inscriptions of Kourion (Vol. 83). Memoirs of the American philosophical society.

Nicolucci, F., Hermon, S., 2010: Five years later. The London Charter Revisited.

Oetelaar, T., 2014. Reconstructing the Baths of Caracalla. Digital Applications in Archaeology and Cultural heritage, Vol. 1, Issue 2, pp. 45-54.

Porcelli, V., Cotino Villa, F., Blasco I Senabre, J., 2013. Integration of 3D Laser Scanning and Virtual Reconstructions as Research and Educational Tools for Representing the Past. The Case Study of Roman Baths of Edeta. Proc. 40th Annual Conference of Computer Applications and Quantitative Methods in Archaeology (CAA), Southampton, 26-29 March 2012, 131142

Remondino, F., Gruen, A., von Schwerin, J., Eisenbeiss, H., Rizzi, A., Sauerbier, M., Richards-Rissetto, H., 2009. Multisensors 3D documentation of the Maya site of Copan. Proc. of 22nd CIPA Symposium, 11-15 Oct., Kyoto, Japan.

Rubinich, M., 2011. New Technologies for the Great Baths of Aquileia: Results and Prospects. Proceedings of the New Technologies for Aquileia, Proceedings of the 1st Workshop, Aquileia, Italy, May 2, 2011.

Scranton, R., 1967. The Architecture of the Sanctuary of Apollo Hylates at Kourion, Transactions of the American Philosophical Society 57.5, Philadelphia: American Philosophical Society.

Stylianidis, E., Georgopoulos, A., Remondino, F. (2016). Basics of Image-Based Modelling Techniques in Cultural Heritage (Chapter pp. 253-301). In: 3D Recording, Documentation and Management of Cultural Heritage. 
ISPRS Annals of the Photogrammetry, Remote Sensing and Spatial Information Sciences, Volume IV-2/W2, 2017 26th International CIPA Symposium 2017, 28 August-01 September 2017, Ottawa, Canada

Vico, L., Vassallo, V., 2010. Methodologies and Techniques for the Reconstruction of Ancient Architectures. Proceedings of the 38th Annual Conference on Computer Applications and Quantitative Methods in Archaeology, CAA2010. 